\title{
Program STEPPS kot možna oblika pomoči posameznikom z mejno osebnostno motnjo
}

\author{
Jerica Radež ${ }^{*}$ in Meta Shawe-Taylor ${ }^{2}$ \\ ${ }^{1}$ Ljubljana \\ ${ }^{2}$ Surrey and Borders Partnership NHS Foundation Trust, Leatherhead, Surrey, Velika Britanija
}

\begin{abstract}
Povzetek: Mejna osebnostna motnja je kompleksna psihična motnja, ki pomembno vpliva na vsa področja posameznikovega delovanja. Ker predstavlja najpogostejšo motnjo osebnosti na populaciji bolnikov z duševnimi motnjami in ker je relativno odporna na farmakološko zdravljenje, je oblikovanje učinkovitih psihoterapevtskih pristopov ključnega pomena za nadaljnjo obravnavo teh bolnikov. V preteklosti je bilo razvitih več psihoterapevtskih metod, ki so namenjene posameznikom z mejno osebnostno motnjo. Le-te po večini izhajajo iz dveh večjih terapevtskih paradigem, in sicer kognitivno-vedenjske in psihoanalitične. V zadnjem času pa se spodbuja raziskovanje pristopov, ki vključujejo elemente različnih psihoterapevtskih smeri. Enega izmed takšnih predstavlja program STEPPS, ki poleg različnih metod kognitivno-vedenjske terapije vključuje tudi elemente sistemske terapije. Program STEPPS je 20-tedenski program skupinske psihoterapije za posameznike z mejno osebnostno motnjo. Za razliko od večine preostalih pristopov je zasnovan kot podpora obstoječemu načinu zdravljenja. V pričujočem članku predstavljamo osnovne značilnosti programa STEPPS in pregled dosedanjih študij, ki so proučevale njegovo učinkovitost pri zdravljenju posameznikov z mejno osebnostno motnjo. Poleg tega ponujamo kritično oceno programa STEPPS v kontekstu dosedanjih psihoterapevtskih pristopov in predlagamo smernice za njegovo nadaljnje raziskovanje.
\end{abstract}

Ključne besede: mejna osebnostna motnja, STEPPS, kognitivno-vedenjska terapija, družinska sistemska terapija, učinkovitost psihoterapije

\section{The STEPPS Group Treatment Program as an alternative in helping people with borderline personality disorder}

\author{
Jerica Radež ${ }^{*}$ and Meta Shawe-Taylor ${ }^{2}$ \\ 'Ljubljana, Slovenia \\ ${ }^{2}$ Surrey and Borders Partnership NHS Foundation Trust, Leatherhead, Surrey, Great Britain
}

\begin{abstract}
Borderline personality disorder is a complex mental disorder which has severe impact on the quality of an individual's life. Although it is the most common type of personality disorder in the population of people with mental disorders, it has so far proven to be rather resistant to pharmacological treatments. This may suggest that effective psychotherapeutic methods need to be developed to help people with this diagnosis. There have been several attempts to develop successful therapeutic interventions for borderline personality disorder. Most of them were developed either from cognitive-behavioural or from psychoanalytic paradigm. More recent studies have focused on developing a more holistic approach. One such approach is the STEPPS program. This programme combines elements from cognitive-behavioural and systemic approaches. STEPPS is a 20week, manually based group treatment for patients with borderline personality disorder. In comparison with other established approaches, the STEPPS program does not interfere with patient's other ongoing treatments. In this article we present the basics of the STEPPS program. We also provide a review of studies, investigating the effectiveness of the program. We also discuss advantages and disadvantages of the program and suggest some topics for further research.
\end{abstract}

Key words: borderline personality disorder, STEPPS, cognitive-behavioural therapy, systemic psychotherapy, psychotherapy effectiveness 
Mejna osebnostna motnja (MOM) je motnja osebnosti, ki jo zaznamuje ponavljajoči vzorec nestabilnosti $\mathrm{v}$ medosebnih odnosih, samopodobi in čustvovanju ter nepredvidljivo in impulzivno vedenje. Ostale značilnosti MOM so strah pred realno ali namišljeno zapustitvijo, motnje identitete, samomorilne geste in samodestruktivno vedenje, kronični občutki praznine, močna in neobvladljiva čustva jeze ter paranoidni in disociativni simptomi. MOM se skupaj $\mathrm{z}$ antisocialno, histrionično in narcisistično osebnostno motnjo uvršča v Skupino B osebnostnih motenj, ki jih imenujemo tudi dramatične osebnostne motnje (American Psychiatric Association [APA], 2013). Pogostost MOM je bila v preteklosti ocenjena na približno 1 \% splošne populacije (npr. Widiger in Weissman, 1991), rezultati kasnejših epidemioloških študij pa kažejo, da kriterijem MOM zadovoljuje kar od 3 (npr. Tomko, Trull, Wood in Sher, 2014) do 6 \% splošne populacije (npr. Grant idr., 2008). Pogostost MOM je še višja pri kliničnih populacijah, in sicer naj bi se pojavljala pri skoraj četrtini psihiatrične populacije (Korzekwa, Dell, Links, Thabane in Webb, 2008), s čimer predstavlja najpogostejšo motnjo osebnosti na populaciji bolnikov $\mathrm{z}$ duševnimi motnjami (Widiger in Weissman, 1991).

\section{Psihoterapevtska obravnava posameznikov z MOM}

MOM je kompleksna psihična motnja, ki je relativno odporna na učinke farmakološkega zdravljenja (npr. Ripoll, 2013). Številne mednarodne smernice (npr. APA, 2001) zato navajajo psihoterapevtsko pomoč posameznikom z MOM kot primarno sredstvo njihove obravnave. Kljub priporočilom smernic je potrebno poudariti, da zaradi zahtevnosti dela s posamezniki $\mathrm{z}$ MOM ni splošno sprejetega konsenza o uporabi točno določenega psihoterapevtskega pristopa. Ti klienti so namreč nagnjeni $\mathrm{k}$ prehitremu zaključku terapije (npr. Skodol, Buckley in Charles, 1983), poleg tega pa s svojimi osebnostnimi lastnostmi povzročajo večjo količino emocionalnega distresa in kontratransfernih reakcij pri psihoterapevtih (npr. Bourke in Grenyer, 2013). Oblikovanje učinkovitih, ustreznih in empirično podprtih psihoterapevtskih pristopov zato predstavlja pomemben izziv sodobnim zdravstvenim sistemom (Zanarini, 2009).

Dosedanje oblike psihoterapevtskih intervencij za pomoč posameznikom z MOM izvirajo predvsem iz dveh širšihteoretskih paradigem: psihoanalitične in kognitivnovedenjske (Yeomans, Levy in Meehan, 2012). Kanadski raziskovalci (Dixon-Gordon, Turner in Chapman, 2011) so pred kratkim izvedli metaanalizo, v okviru katere so proučevali učinkovitost posameznih psihoterapevtskih pristopov pri zdravljenju motenj osebnosti. Ugotovili so, da so za pomoč posameznikom z MOM najbolj empirično podprte naslednje štiri vrste psihoterapije: dialektična vedenjska terapija (angl. Dialectical behavior therapy; Linehan, 1993), terapija, usmerjena na sheme (angl.
Schema therapy; Young, 1999), »psihoterapija, temelječa na mentalizaciji« (angl. Mentalization based therapy; Bateman in Fonagy, 2001) in »na transfer usmerjena psihoterapija « (angl. Transference focused psychotherapy; Clarkin, Yeomans in Kernberg, 1999). Pri tem lahko prvi dve obliki umestimo pod kognitivno-vedenjske, drugi dve pa pod psihoanalitsko orientirane pristope. Poleg že navedenih oblik psihoterapij rezultati raziskav kažejo, da na zmanjšanje števila simptomov MOM vplivajo tudi številni drugi psihoterapevtski pristopi. V preostalih študijah (npr. Blum idr., 2008; Davidson idr., 2006; Marziali in Munroe-Blum, 1995) so se tako kot učinkovite pokazale še individualna in skupinska psihoanalitična terapija, klasična kognitivno-vedenjska terapija (Beck, Freeman in Davis, 2004), »terapija sprejemanja in zavezanosti« (angl. Acceptance and commitment therapy; Hayes, Strosahl in Wilson, 1999), metakognitivna terapija (Wells, 2009) ter program STEPPS (angl. Systems Training for Emotional Predictability and Problem Solving; Blum, Pfohl, St. John, Monahan in Black, 2002). Pri slednjem gre za relativno nov psihoterapevtski pristop, ki temelji na principih kognitivno-vedenjske ter družinske sistemske terapije. Ker je pri nas program STEPPS še relativno nepoznan in ker v tujini njegova uporaba trenutno kaže na precej obetavne izide (npr. Van Wel idr., 2006; Blum idr., 2008), bomo v nadaljevanju predstavili njegove osnovne značilnosti. Poleg tega bomo predstavili pregled dosedanjih študij, ki so proučevale učinkovitost navedenega programa pri obravnavi posameznikov z MOM.

\section{O programu STEPPS}

STEPPS program je 20-tedenski program skupinske psihoterapije za pomoč nehospitaliziranim posameznikom z MOM. Temelji na principih kognitivno-vedenjske terapije in delno družinske sistemske terapije. Program je izrazito psihoedukativen - namenjen je zlasti učenju veščin za uravnavanje čustvenih reakcij in vedenja posameznikov z MOM. Izvedba programa STEPPS natančno sledi navodilom, ki so jih v okviru obsežnega priročnika natančno opisali avtorji programa (Blum idr., 2002).

Pred nastankom programa STEPPS sta imela empirične dokaze o učinkovitosti zgolj dva izmed predhodno navedenih pristopov, in sicer dialektična vedenjska terapija (Linehan, 1993) in »psihoterapija, temelječa na mentalizaciji« (Bateman in Fonagy, 2001). Ker sta oba psihoterapevtska pristopa zasnovana tako, da zahtevata posebej usposobljene izvajalce ter pogoste (več kot enkrat tedenske) psihoterapevtske obravnave, je njuna izvedba precej draga. Zaradi pogostosti srečanj pa sta tudi logistično težje izvedljiva $\mathrm{v}$ okviru programov zdravljenja v skupnosti (Black, Blum, Pfohl in St. John, 2004). Izvedba intenzivnih psihoterapevtskih programov za pomoč nehospitaliziranim posameznikom z MOM je še posebej otežena $\mathrm{v}$ velikih državah, denimo $\mathrm{v}$ ZDA, 
kjer so razdalje med posameznimi kraji prevelike, da bi uporabnikom omogočale večkrat tedensko vožnjo do večjih zdravstvenih centrov. Zaradi navedenih praktičnih pomanjkljivosti so ameriški raziskovalci iz zvezne države Iowe (Blum idr., 2002) razvili nov psihoterapevtski program STEPPS. Pri oblikovanju programa so poleg že omenjenih vodil, to so široka dostopnost, stroškovna in časovna ekonomičnost in malo dodatnega učenja za izvajalce, želeli ustvariti program, ki ne bo motil posameznikove tekoče psihološke in/ali farmakološke oskrbe (Black idr., 2004).

\section{Teoretično ozadje}

Teoretično ozadje programa STEPPS predstavlja razlaga MOM po principih dialektične vedenjske terapije. Jedro težav posameznikov z MOM naj bi predstavljale težave $\mathrm{z}$ regulacijo intenzivnosti čustvovanja, kar vodi $\mathrm{v}$ neprilagojena in disfunkcionalna vedenja (Linehan, 1993). Ker je pri opredelitvi M. Linehan (1993) izpostavljen zlasti vidik težav z regulacijo intenzivnosti čustvovanja, se tekom programa namesto izraza MOM uporablja izraz motnja intenzivnosti čustvovanja (angl. Emotional Intensity Disorder - EID). Gre za izraz, ki sta ga pred skoraj dvema desetletjema predlagala Bartels in Crotty (1998). Poleg tega, da izraz bolje povzema glavne značilnosti posameznikov z MOM, je tudi bolje sprejet pri pacientih, saj se jim zdi manj podcenjujoč od izraza MOM in jim daje občutek večje obvladljivosti njihovih težav (Black idr., 2004). Drugo pomembnejše teoretično izhodišče programa STEPPS pa predstavljajo principi sistemske terapije (Minuchin, 1974), po katerih so neprilagojena vedenja vzdrževana s strani družinskega sistema in ostalih sistemov, ki jih tvorijo na primer posameznikovi prijatelji, sodelavci in zdravstveni delavci. Pri spreminjanju neustreznih vedenj je torej potrebno spremeniti tudi odziv sistemov na ta vedenja. Program STEPPS zato spodbuja vključevanje ostalih članov "ssistema«, tj. sorodnikov, prijateljev in zdravstvenih delavcev. Do konca programa naj bi se posameznik naučil (kognitivno-vedenjska komponenta) ustreznih načinov regulacije čustvene intenzitete, njegovo okolje (sistemska komponenta) pa naj bi prilagojene vedenjske vzorce spodbujalo in nagrajevalo (Black idr., 2004).

\section{Osnovne značilnosti izvedbe}

V program STEPPS se lahko vključijo posamezniki z diagnosticirano MOM, ki so s svojo diagnozo seznanjeni. Pred vključitvijo v program se morajo udeleženci zavezati, da bodo sodelovali $\mathrm{v}$ dvajsetih skupinskih srečanjih. Pogoj za vključitev v program so tudi vsaj povprečne intelektualne sposobnosti ter sposobnost skupinskega učenja. Pri udeležencih, ki imajo poleg simptomov MOM tudi močno izražene narcisistične poteze, motnje hranjenja ali so močno zasvojeni s katero izmed psihoaktivnih snovi, se vključitev v program STEPPS odsvetuje (Black idr., 2004).
Izvedba programa STEPPS traja dvajset tednov in vključuje dvourna srečanja enkrat tedensko. Izmed dvajsetih srečanj lahko vsak udeleženec izostane največ trikrat. Posamezniki, ki zamudijo več kot tri srečanja, so avtomatsko izključeni iz programa. Izključitev iz programa pri tem ne sme biti obravnavana kot kazen, temveč mora biti posameznikom jasno predstavljeno, da je ob večkratnem izostanku zamujenih preveč pomembnih vsebin, kar vpliva na slabšo učinkovitost programa. V skupini programa STEPPS sta po navadi prisotna dva terapevta in od 6 do 10 posameznikov $\mathrm{z}$ MOM. Ker je program naravnan zelo edukativno, je sama psihoterapevtska situacija podobna situaciji $\mathrm{V}$ učilnici. Udeleženci skupine tako sedijo okoli mize in spremljajo razlago ob tabli. Vsak udeleženec skupine na začetku programa dobi svojo mapo z izročki, ki jo dopolnjuje $\mathrm{v}$ okviru preostalih srečanj. Vsa srečanja so konceptualno zastavljena enako. V uvodnem delu poteka izpolnjevanje lestvice izrazitosti simptomov MOM (vprašalnik Borderline Evaluation of Severity over Time-BEST; Pfohl in Blum, 1997), pregled domače naloge preteklega srečanja, pregled t.i. stalnih domačih nalog (npr. Kontinuuma intenzitete čustev), kratka vaja sproščanja ipd. V osrednjem delu skupina obravnava eno od dvajsetih vsebinskih tem. V zaključnem delu pa posamezniki dobijo nalogo za naslednji teden in srečanje zaključijo $\mathrm{z}$ dodatnimi vprašanji in diskusijo. Vsebine dvajsetih srečanj programa STEPPS lahko združimo $\mathrm{v}$ tri nadredne sklope. V prvi fazi se posveča največ pozornosti prepoznavanju motnje in njenih značilnosti. $\mathrm{V}$ drugi fazi se skupina največ posveča učenju spretnosti čustvene regulacije, med katere sodijo na primer spretnost distanciranja od intenzivnega čustvenega doživljanja in spretnost komuniciranja o čustvenem doživljanju. Tretja faza programa pa udeležencem nudi zlasti informacije o učinkovitih vedenjskih strategijah, ki jim pomagajo pri obvladovanju MOM. Med vedenjske strategije sodi na primer oblikovanje ustreznih prehranjevalnih in spalnih navad (Black idr., 2004).

\section{Vključevanje sistemske komponente}

Za posameznike z MOM je značilno, da njihove neučinkovite vzorce vedenja vzdržujejo in podkrepljujejo reakcije njihovih bližnjih (npr. družinskih članov, partnerjev ali prijateljev). Ker se tekom programa pacienti učijo novih spretnosti uravnavanja čustvene intenzivnosti, je zato nujno, da so nove vedenjske strategije podkrepljene tudi s strani okolja. Program STEPPS vključuje okolje na različnih nivojih. Na nivoju terapevtske skupine nova vedenja spodbujajo ostali člani skupine in vodje skupine (terapevti). Poleg tega se člane skupine spodbuja k temu, da delijo gradivo programa tudi s svojimi bližnjimi. Tretja oblika spodbujanja vključevanja posameznikovega okolja pa so večerna srečanja, na katera so poleg posameznikov, vključenih v program, vabljeni tudi njihovi pomembni bližnji. V okviru večernih srečanj imajo tudi slednji možnost bolje spoznati lastnosti MOM in njene obravnave (Black idr., 2004). 


\section{Vodenje skupine in potrebna izobrazba vodij}

Program STEPPS po navadi vodita dva strokovnjaka, ki se poskušata čim bolj držati psihoedukativne oblike skupine in programa posameznega srečanja, kot ga določa priročnik. Poleg tega je zaželeno, da se vodje osredotočajo na skupno učenje spretnosti in ne na težave posameznikov. Vodje morajo torej paziti, da posamezno srečanje ne postane pogovor o težavah posameznega udeleženca. Zaradi tega je tudi priporočljivo, da vodje skupine nimajo individualnega psihoterapevtskega odnosa s člani skupine (Black idr., 2004).

Izobraževanje za vodenje programa običajno poteka $\mathrm{v}$ okviru dvodnevne delavnice, kjer so slušatelji natančno seznanjeni z značilnostmi MOM in principi obravnave po programu STEPPS (Blum idr., 2002). Kar se tiče osnovne izobrazbe, avtorji programa priporočajo, da ima vodja skupine vsaj drugostopenjsko univerzitetno izobrazbo s področja družbenih ved. Poleg tega priporočajo, da imajo vodje vsaj nekaj let izkušenj s svetovalnim delom in/ali psihoterapijo (Black idr., 2004).

\section{Dokazi o učinkovitosti programa STEPPS}

Ker je program STEPPS relativno nov pristop za pomoč posameznikom z MOM, je število raziskav, ki bi proučevale njegovo učinkovitost, precej majhno. Avtorji programa (Blum idr., 2002) so v preliminarni raziskavi ugotovili, da je program dobro sprejet tako s strani pacientov kot tudi s strani izvajalcev. Poleg tega so pri udeležencih programa zabeležili pomembno nižjo stopnjo simptomov MOM. Pri tem je bila največja razlika v stopnji izraženosti negativnih vedenj, ki se je najbolj pomembno zmanjšala. Raziskovalci so ugotovili tudi pozitiven učinek programa na razpoloženje posameznikov, in sicer se je pri udeležencih najbolj signifikantno zmanjšala stopnja doživljanja negativnih emocij. Do podobnih rezultatov so v okviru dveh preliminarnih študij prišli tudi britanski raziskovalci. V prvo študijo (Harvey, Black in Blum, 2010) je bilo vključenih 38 posameznikov z MOM. Raziskovalci so ugotovili, da je izvedba programa STEPPS vplivala na zmanjšanje različnih simptomov MOM. Poleg tega je pri uporabnikih prišlo do pomembnega izboljšanja razpoloženja, in sicer tako na področju negativnega čustvovanja (pomembno zmanjšanje) kot na področju pozitivnega čustvovanja (pomembno povečanje). Druga britanska študija (Shawe-Taylor, Geoghegan in Hill, v tisku) pa je vključevala 45 udeležencev. Podobno kot pri predhodni raziskavi so tudi tu raziskovalci zabeležili pomemben upad večine simptomov MOM pri udeležencih. Poleg tega se je pri posameznikih, vključenih $\mathrm{v}$ program STEPPS, pomembno izboljšala kakovost življenja. Raziskovalci pa so zabeležili tudi izboljšanje na kognitivnem področju, in sicer je pri udeležencih prišlo do pomembnega izboljšanja specifičnih kognitivnih distorzij, ki jih avtorji programa imenujejo negativni filtri. Avtorji vseh treh preliminarnih raziskav predlagajo nadaljnje raziskovanje učinkovitosti programa STEPPS, pri čemer zlasti spodbujajo raziskovanje $\mathrm{V}$ okviru randomiziranih kontroliranih poskusov. Enega izmed takih poskusov so izvedli nizozemski raziskovalci (Bos, van Wel, Appelo in Verbraak, 2010), in sicer na vzorcu 66 posameznikov z diagnosticirano MOM, od katerih je bila polovica vključenih $\mathrm{v}$ program STEPPS in dodatno individualno psihoterapijo, polovica udeležencev pa je bila obravnavanih po običajnem postopku, torej so bili deležni zgolj individualne psihoterapije. Po končanem programu so raziskovalci $\mathrm{z}$ različnimi pripomočki preverjali, kolikšen je učinek obeh pogojev na zmanjšanje simptomov MOM in na kakovost življenja posameznikov. Pri tem so jih zlasti zanimale razlike med skupinama. Ugotovili so, da je pri skupini udeležencev, ki so bili vključeni v program STEPPS, prišlo do pomembnejšega upada večine simptomov MOM (z izjemo samomorilnih gest in impulzivnosti) ter splošnih psihiatričnih simptomov. Poleg tega so ti udeleženci kazali tudi boljše rezultate na lestvici kakovosti življenja. Avtorji so v nadaljevanju proučevali tudi velikosti učinkov za razlike med skupinama. Ugotovili so, da so vrednosti Cohenovega $d$ koeficienta od srednje do visoke, kar kaže na pomembno praktično vrednost ugotovitev. Raziskovalce je $\mathrm{v}$ nadaljevanju zanimalo tudi, ali so te spremembe obstojne oz. ali bodo razlike med udeleženci prisotne tudi po polletnem zamiku. Ugotovili so, da udeleženci programa STEPPS tudi kasneje kažejo manj simptomov MOM. Še zlasti pa je bil zanimiv podatek, da so bile razlike med skupinama udeležencev v kakovosti življenja čez pol leta še večje kot takoj po zaključku programa. Navedeno bi lahko kazalo na to, da vključitev v program STEPPS dolgoročno vpliva na boljšo kakovost življenja posameznikov z MOM. Raziskovalci so ponovili podobno študijo tudi leto dni kasneje (Bos, van Wel, Appelo in Verbraak, 2011). Za razliko od predhodne študije so tu vključili večji vzorec posameznikov, in sicer skupno kar 168 ljudi, pri katerih je zdravstveno osebje identificiralo poteze MOM. Vzorec so tako predstavljali skupnostno zdravljeni posamezniki $\mathrm{z}$ izraženimi potezami MOM in ne nujno $\mathrm{z}$ diagnozo MOM. Posledično je bil vzorec v tej študiji bolj heterogen in je vseboval tudi posameznike, ki so zadovoljevali kriterijem več kot ene osebnostne motnje. Podobno kot pri prejšnji študiji so tudi tukaj avtorji proučevali razlike med skupinama udeležencev, ki so prejemali zgolj individualno psihoterapevtsko podporo, in tistimi, ki so bili poleg individualne podpore vključeni v program STEPPS. Razlike med skupinama so primerjali tako na kratkoročni kot tudi na dolgoročni ravni. Ugotovili so, da je skupina udeležencev, ki so bili vključeni v program STEPPS, izražala manjšo mero simptomov MOM in splošnih psihiatričnih simptomov ter boljšo kakovost življenja. Razlike med skupinama so bile pomembne takoj po izvedbi programa in po polletnem zamiku. Avtorji zato zaključujejo, da je aplikacija programa učinkovita tudi pri posameznikih, ki poleg simptomov MOM izražajo tudi simptome ostalih osebnostnih motenj in ostalih psihiatričnih težav. 
Podobno študijo, ki je vključevala randomizirane kontrolirane poskuse, so izvedli tudi ameriški raziskovalci (Blum idr., 2008). Od 96 udeležencev z diagnozo MOM, ki so že prejemali vsaj enega od obstoječih načinov podpore (npr. individualna psihoterapija in medikamentozno zdravljenje), je bilo 45 udeležencev vključenih v program STEPPS. Raziskovalce je zanimalo, ali bo med skupinama udeležencev prišlo do pomembnih razlik $\mathrm{v}$ različnih psihosocialnih vidikih delovanja. Pri tem so jih zlasti zanimale razlike v stopnji izraženosti simptomov MOM, stopnji doživljanja pozitivnih in negativnih emocij, stopnji depresivnosti in $\mathrm{v}$ ravni socialne prilagojenosti. Po dvajsetih tednih od začetka vključitve udeležencev v program STEPPS so primerjali udeležence obeh skupin in ugotovili pomembne razlike med skupinama na številnih področjih funkcioniranja. Skupina udeležencev, ki je bila poleg običajnega zdravljenja vključena v program STEPPS, je dosegla pomembno boljše rezultate na večini lestvic simptomov MOM, na Beckovi lestvici depresivnosti in na lestvici socialne prilagojenosti. Poleg tega so posamezniki, vključeni v program, izražali manjšo mero negativnih emocij kot ostali udeleženci. Po drugi strani pa razlike v stopnji doživljanja pozitivnih emocij ter $\mathrm{v}$ pogostosti samomorilnih gest, samopoškodovalnega vedenja in hospitalizacij med skupinama niso bile pomembne. Ker je raziskovalce zanimalo, kako obstojni so učinki programa STEPPS, so večino udeležencev ponovno preizkusili eno leto po izvedbi programa. Ugotovili so, da so na večini področij razlike med udeleženci ostale pomembne tudi po enem letu, kar kaže na ugodne dolgoročne učinke programa STEPPS na psihosocialno funkcioniranje posameznikov z MOM.

Za konec velja omeniti še najnovejšo raziskavo italijanskih avtorjev (Alesiani, Boccalon, Giarolli, Blum, in Fossati, 2014), v okviru katere so na manjšem ( $n=$ 32) vzorcu posameznikov z MOM in pridruženo motnjo razpoloženja proučevali učinek programa STEPPS na različne simptome MOM. Ugotovili so, da je bila pri posameznikih po izvedbi programa prisotna pomembno nižja stopnja samomorilnih gest in hospitalizacij. Te pozitivne spremembe v vedenjih so se izkazale kot precej stabilne tudi pri ponovni oceni udeležencev, ki je potekala z 12-mesečnim zamikom. Po drugi strani pa avtorji niso ugotovili pomembnih sprememb na kognitivnem področju, tj. na področju kognitivnih distorzij, imenovanih negativni filtri. Avtorji zato zaključujejo, da je vpliv programa STEPPS bolj ugoden na področju uravnavanja vedenja in čustvovanja kot na kognitivnem področju. Kljub temu, da navedena študija ni vključevala randomiziranih kontroliranih poskusov, so avtorji raziskave opozorili na nekatera pomembna dejstva. Ker so bili v študijo vključeni posamezniki, pri katerih so bile prisotne tako motnje prve osi DSM-IV, kot tudi posamezniki, ki so zadovoljevali kriterijem nekaterih ostalih osebnostnih motenj, so raziskovalci proučevali tudi povezanost med dokončanjem programa in osebnostnimi lastnostmi posameznikov, vključenih $\mathrm{v}$ program. Ugotovili so, da na vztrajanje $\mathrm{v}$ programu najbolj negativno vplivajo simptomi histrionične motnje osebnosti in pomanjkanje samoodločenosti ter sposobnosti sodelovanja. Pri posameznikih, ki niso zaključili programa, so bile tudi $\mathrm{v}$ večji meri prisotne osebnostne poteze, ki se povezujejo $z$ večjo mero duhovnih izkustev in zaznavanjem sebe kot pomembnega dela univerzuma (tj. samotranscendentne poteze), kar kaže na nekoliko slabši stik z realnostjo pri teh posameznikih. Napovednike učinkovitosti in vztrajanja $\mathrm{v}$ programu STEPPS so proučevali tudi Black in sodelavci (2009). Ugotovili so, da je predčasna opustitev programa pozitivno povezana $\mathrm{Z}$ višjo ravnjo impulzivnosti in negativno povezana $\mathrm{s}$ količino psihotropnih zdravil, ki so jih jemali udeleženci. Raziskovalci so kasneje proučevali, katere lastnosti udeležencev so povezane $\mathrm{s}$ samo učinkovitostjo programa STEPPS. Ugotovili so, da je imel program najboljše učinke na udeležence, ki so pred izvedbo poročali o večjih količinah simptomov MOM. Nekoliko večji učinek programa so raziskovalci zabeležili tudi pri udeležencih moškega spola. Pri tem je potrebno poudariti, da pri moških udeležencih ni prišlo do pomembno večjega upada simptomov MOM, temveč le do pomembno boljših dosežkov na lestvicah za ocenjevanje splošne učinkovitosti programov. Razlike v učinkovitosti programa glede na spol je zato potrebno interpretirati $\mathrm{s}$ pazljivostjo. Kot zadnji in pomembni napovednik učinkovitosti programa STEPPS so avtorji izpostavili podatek o številu srečanj, ki so se jih udeležili udeleženci. Učinkovitost programa je bila namreč pomembno večja pri tistih posameznikih, ki so se udeležili vsaj petnajstih srečanj. Zaradi empirično podprte slabše učinkovitosti programa pri manj kot petnajstih srečanjih so kasneje avtorji programa uvedli pravilo maksimalnega izostanka treh srečanj.

\section{Perspektive za naprej}

Dokazi o učinkovitosti programa STEPPS na populaciji bolnikov z MOM (npr. Blum idr., 2008) so spodbudili raziskovanje učinkovitosti programa na drugih kliničnih skupinah. Riemann idr. (2014) so na primer zasnovali obsežno študijo, v okviru katere bodo proučevali učinek programa STEPPS na vzorcu posameznikov, ki imajo poleg MOM diagnosticirano tudi bipolarno motnjo. Mnogi simptomi MOM in bipolarne motnje so namreč podobni, zato raziskovalci pričakujejo, da bo tudi pri drugi skupini posameznikov prišlo do pomembnega upada simptomov MOM in do pomembnega izboljšanja kakovosti življenja. Raziskovalci bodo tudi proučevali, ali program STEPPS vpliva na zmanjšanje depresivnih simptomov in maničnih simptomov. Rezultati raziskave bodo pomembni, saj bodo omogočili boljše razumevanje sovpadanja diagnoz MOM in bipolarne motnje. Poleg tega bodo pokazali, ali je aplikacija programa STEPPS učinkovita tudi pri drugih kliničnih skupinah. Na podlagi izsledkov raziskave bodo lahko raziskovalci oblikovali nadaljnje smernice za delo $\mathrm{s}$ posamezniki z bipolarno motnjo in MOM. 
Poleg raziskovanja ugodnih učinkov programa STEPPS na ostale klinične skupine udeležencev raziskovalci proučujejo tudi njegovo učinkovitost $\mathrm{V}$ drugačnih kontekstih. Avtorji programa (Black, Blum, McCormick in Allen, 2013) so pred kratkim proučevali učinkovitost programa na večjem vzorcu kaznjencev. Izmed 77 udeležencev, vključenih v program, je bilo 14 udeležencev moškega in 66 udeleženk ženskega spola. Vsi udeleženci so imeli diagnosticirano MOM. Raziskovalce je zanimalo, ali bo izvedba programa STEPPS vplivala na upad simptomov MOM, na stopnjo pozitivnih in negativnih emocij in na stopnjo depresivnosti kaznjencev. Rezultati so pokazali na pozitivne učinke programa, saj je po izvedbi prišlo do pomembnega upada simptomov MOM, izboljšanja razpoloženja in do upada stopnje negativnega čustvovanja. Ti rezultati so skladni $\mathrm{s}$ preteklimi študijami v običajnem okolju oz. skupnostni obravnavi posameznikov z MOM (npr. Blum idr., 2008). Zanimivo je to, da se je po izvedbi programa pomembno zmanjšalo število samopoškodovalnih vedenj in število disciplinskih ukrepov kaznjencev, vključenih v program. Avtorji (Black idr., 2013) zato zaključujejo, da bi bilo program STEPPS smiselno aplicirati tudi $\mathrm{v}$ inštitucijah, namenjenim prevzgoji in korekciji vedenja posameznikov.

Kljub temu, da je raziskav na temo aplikacije programa STEPPS $\mathrm{v}$ ostalih kliničnih in nekliničnih kontekstih relativno malo, pa naj bi se v praksi STEPPS že izvajal v številnih raznolikih oblikah. Van Wel idr. (2006) v svojem preglednem članku navajajo, da v Evropi poleg klasične izvedbe programa poteka tudi program STEPPS za svojce posameznikov z MOM ter različica za mame $\mathrm{z}$ MOM in njihove otroke. V Združenih državah Amerike pa izvajajo prilagojene različice programa STEPPS za delo $\mathrm{z}$ odvisniki, adolescenti, posamezniki $\mathrm{z}$ nižjimi intelektualnimi sposobnostmi, zaporniki in mladoletnimi prestopniki. Poleg tega, da narašča število prilagoditev programa za delo s posameznimi skupinami udeležencev, narašča tudi število prevodov in priredb programa za druga jezikovna okolja. V Evropi je tako STEPPS poznan že v Veliki Britaniji, na Nizozemskem, v Belgiji, Nemčiji, Italiji in na Norveškem.

\section{Kam po programu STEPPS?}

Izvedba programa STEPPS temelji na skupinskem procesu, zato se tekom programa ves čas spodbuja medsebojno sodelovanje, razumevanje in podpora. Zaključek programa in $\mathrm{s}$ tem prenehanje pripadnosti terapevtski skupini lahko posledično pri posameznikih povzročita občutke tesnobnosti. Da bi v čim večji meri preprečili negativna čustva ob zaključku programa, je ključnega pomena, da vodje skupine ves čas spodbujajo posameznike $\mathrm{k}$ iskanju podpore znotraj svojega obstoječega sistema (tj. pri svojih pomembnih bližnjih). Nekateri udeleženci pa kljub temu želijo ohraniti odnose s preostalimi člani tudi po koncu programa. Vodje skupin lahko v takih primerih spodbujajo neformalna srečanja posameznih članov skupine. $\mathrm{Na}$ ta način si udeleženci programa nudijo medsebojno podporo tudi po koncu STEPPS-a. Druga možnost podpore udeležencem po zaključku programa STEPPS je ponoven vpis v skupino. Ta alternativa je zlasti ustrezna za tiste posameznike, ki zaradi različnih razlogov niso mogli dobro slediti terapevtskemu programu. Tretja možnost, ki jo imajo po zaključku udeleženci programa STEPPS, pa je program STAIRWAYS (angl. Setting goals, Trying new things, Anger management, Impulsivity control, Relationship behaviors, Writing a script, Assertiveness training, Your choices, and STEPPing out revisited). Gre za enoletni program, ki poteka $\mathrm{v}$ obliki dveh srečanj na mesec. Cilj programa je ohranjanje spretnosti, ki so se jih udeleženci naučili tekom programa STEPPS, ter učenje dodatnih spretnosti. Med te sodijo na primer zastavljanje novih ciljev, trening asertivnosti, obvladovanje jeze in obvladovanje impulzivnosti. Udeleženci tekom programa prejmejo dodatno gradivo. Program STAIRWAYS tako po eni strani pomaga vzdrževati spretnosti, naučene tekom programa STEPPS, po drugi strani pa je koristen tudi za zmanjševanje občutkov tesnobnosti ob zaključku programa STEPPS (Black idr., 2004). Britanski raziskovalci (Shawe-Taylor idr., v tisku) poleg že navedenih možnosti po zaključku programa priporočajo še nekatere dodatne oblike aktivnosti za posameznike, ki so zaključili program STEPPS. Ena od njih je na primer vključevanje udeležencev, ki so bili s programom še posebej zadovoljni, v kasnejša izvajanja programa. Vključevanje primerov dobre prakse naj bi pozitivno vplivalo na posameznike, vključene v skupine v izvajanju. Hkrati pa naj bi se krepili pozitivni občutki pri posameznikih, ki so že uspešno zaključili program.

\section{Zaključek}

V prispevku smo predstavili program STEPPS (Blum idr., 2002) kot možno alternativo za psihoterapevtsko obravnavo posameznikov $\mathrm{z}$ MOM. $\mathrm{V}$ primerjavi $\mathrm{z}$ dosedanjimi psihoterapevtskimi pristopi ima program STEPPS določene objektivne prednosti, saj je vsestransko bolj ekonomičen, vključuje sistemsko komponento in ne moti obstoječega načina zdravljenja. V prid uporabi programa STEPPS govorijo tudi izsledki dosedanjih študij (npr. Blum idr., 2008; Bos idr., 2010), v okviru katerih se je pristop izkazal kot še zlasti učinkovit pri zmanjševanju stopnje simptomov MOM in stopnje doživljanja negativnih emocij. Poleg tega naj bi se na program pozitivno odzivali tako pacienti kot osebje. Novejše raziskave (npr. Black idr., 2013) pa kažejo na potencialno učinkovitost programa tudi v ostalih kontekstih.

Kljub obetavnim rezultatom študij je potrebno poudariti, da je število raziskav, ki so proučevale učinkovitost programa STEPPS v okviru kontroliranih poskusov, zelo majhno. Dokaze o ustreznosti programa je zato potrebno interpretirati s precejšnjo mero pazljivosti. 
Prav tako je potrebno s pazljivostjo interpretirati rezultate študij, ki so proučevale učinkovitost STEPPS-a v drugih kontekstih, sajteštudije ponisovključevalerandomiziranih kontroliranih poskusov. Poleg pomanjkljivih empiričnih dokazov je pri presojanju učinkovitosti in ustreznosti programa STEPPS pomembno upoštevati tudi dejstvo, da program ( $\mathrm{v}$ primerjavi $\mathrm{z}$ nekaterimi dosedanjimi psihoterapevtskimi pristopi) ne nudi celostne podpore posameznikom. To pomeni, da je uporaba programa ustrezna le za tiste posameznike, ki že prejemajo določeno obliko psihiatrične ali psihološke podpore. Iz tega vidika je neposredna primerjava programa STEPPS in pristopov, ki so zasnovani kot celostna podpora posameznikom z MOM (npr. dialektična vedenjska terapija), nekoliko neustrezna. Kot zadnjo omejitev programa pa je potrebno izpostaviti dejstvo, da tudi program STEPPS ne ponuja enoznačnega odgovora na naše začetno vprašanje, torej kateri psihoterapevtski pristop je najbolj ustrezen in učinkovit za paciente z MOM. Kljub temu, da so deleži udeležencev, ki predhodno prekinejo $\mathrm{s}$ programom STEPPS, manjši kot pri večini drugih pristopov (npr. Van Wel, 2006), je izpad udeležencev tudi tukaj v večini primerov vsaj 20 -odstoten. $\mathrm{V}$ prihodnosti bi bilo tako smiselno nadaljevati $\mathrm{z}$ raziskovanjem dejavnikov, ki vplivajo na daljše vztrajanje $\mathrm{v}$ programu in na podlagi izsledkov oblikovati takšne implementacije programa, da bo verjetnost predhodne opustitve zdravljenja čim manjša. Poleg tega bi bilo smiselno nadaljnje proučevanje učinkovitosti programa $\mathrm{v}$ okviru kontroliranih študij, ki bi vključevale različne klinične skupine in bi potekale $\mathrm{v}$ različnih kontekstih. Učinkovitost programa STEPPS bi bilo dobro proučevati tudi v primerjavi z učinkovitostjo preostalih sorodnih psihoterapevtskih pristopov. Na ta način bomo lahko bolje razumeli, katere so specifike programa STEPPS, ki so ključne za spremembe, in ki se povezujejo $\mathrm{z}$ bolj pozitivnim izidom posameznikov z MOM. Za konec velja omeniti še spodbujanje razvoja prevodov programa za različna jezikovna okolja, med drugim za slovensko. Kljub temu da pri nas razdalje med posameznimi kraji niso tako velike kot npr. v ZDA, pa je večjih centrov za psihološko pomoč posameznikom z MOM relativno malo. Poleg tega so centri med seboj precej oddaljeni. S prevodom in priredbo programa STEPPS za slovenske razmere bi tako omogočili širšo dostopnost psihoterapevtske pomoči posameznikom z MOM, saj je program zasnovan tako, da se lahko izvaja tudi v manjših zdravstvenih centrih.

MOM je izredno kompleksna psihična motnja, ki predstavlja pomemben izziv tako posameznim zdravstvenim delavcem kot tudi celotnemu zdravstvenemu sistemu. Oblikovanje enoznačnih smernic o uporabi točno določenegapristopazazdravljenjeteh posameznikovjezato praktično nemogoče. Namesto iskanja najbolj optimalne rešitve je verjetno bolj smiselno spodbujati fleksibilnost in dodatno izobraževanje terapevtov, ki delajo s pacienti z MOM, in oblikovanje takšnih pristopov, ki bodo čim bolj celostno zajeli težave, s katerimi se soočajo posamezniki z MOM (npr. Benedik, 2014). Enega od takšnih pristopov zagotovo predstavlja program STEPPS.

\section{Literatura}

American Psychiatric Association. (2001). Practice guideline for the treatment of patients with borderline personality disorder. Washington, DC, ZDA: American Psychiatric Association.

American Psychiatric Association. (2013). Diagnostic and statictical manual of mental disorders (5. izd.). Washington, DC, ZDA: American Psychiatric Publishing.

Alesiani,R.,Boccalon, S., Giarolli,L.,Blum,N.inFossati,A. (2014). Systems Training for Emotional Predictability and Problem Solving (STEPPS): program efficacy and personality features as predictors of drop-out an Italian study. Comprehensive Psychiatry, 55(4), 920-7. doi:10.1016/j.comppsych.2014.01.003

Bartels, N. in Crotty, T. (1998). A systems approach to treatment: The borderline personality disorder skill training manual. Winfield, IL, ZDA: EID Treatment Systems.

Bateman,A. W.inFonagy,P.(2001). Treatment of borderline personality disorder with psychoanalytically oriented partial hospitalization: An 18-month follow-up. American Journal of Psychiatry, 158, 36-42.

Beck, A. T., Freeman, A. in Davis, D. D. (2004). Cognitive therapy of personality disorders. New York, NY, ZDA: Guildford Press.

Benedik, E. (2014). Za integrirano in celostno psihoterapijo osebnosti: značilnosti psihtoerapevtske obravnave pacientov $\mathrm{z}$ mejno osebnostno motnjo [Towards integrative and holistic psychotherapy: characteristics of psychotherapeutic treatment of patients with borderline personality disorder]. Kairos, 8(1), 12-24.

Black, D. W., Blum, N., Pfohl, B. in St John, D. (2004). The STEPPS group treatment program for outpatients with borderline personality disorder. Journal of Contemporary Psychotherapy, 34(3), 193-210.

Black, D. W., Allen, J., St John, D., Pfohl, B., McCormick, B. in Blum, N. (2009). Predictors of response to Systems Training for Emotional Predictability and Problem Solving (STEPPS) for borderline personality disorder: An exploratory study. Acta Psychiatrica Scandinavica, 120(1), 53-61. doi:10.1111/j.16000447.2008.01340.x

Black, D. W., Blum, N., McCormick, B. in Allen, J. (2013). Systems Training for Emotional Predictability and Problem Solving (STEPPS) group treatment for offenders with borderline personality disorder. The Journal of Nervous and Mental Disease, 201(2), 1249. doi:10.1097/NMD.0b013e31827f6435

Blum, N., Pfohl, B., St. John, D., Monahan, P. in Black, D. W. (2002). STEPPS: A cognitive-behavioral systems-based group treatment for outpatient clients with borderline personality disorder - a preliminary report. Comprehensive Psychiatry, 43, 301-310.

Blum, N., St. John, D., Pfohl, B., Stuart, S., Mccormick, B., Allen, J., Arndt, S. in Black, D. W. (2008). Systems Training for Emotional Predictability and Problem 
Solving (STEPPS) for Outpatients With Borderline Personality Disorder: A randomized trial. American Journal of Psychiatry, 165(4), 468-478.

Bos, E. H., van Wel, E. B., Appelo, M. T. in Verbraak, M. J. P. M. (2010). A randomized controlled trial of a Dutch version of systems training for emotional predictability and problem solving for borderline personality disorder. The Journal of Nervous and Mental Disease, 198(4), 299-304. doi:10.1097/NMD.0b013e3181d619cf

Bos, E. H., van Wel, E. B., Appelo, M. T. in Verbraak, M. J. P. M. (2011). Effectiveness of Systems Training for Emotional Predictability and Problem Solving (STEPPS) for borderline personality problems in a "real-world" sample: Moderation by diagnosis or severity? Psychotherapy and Psychosomatics, 80(3), 173-81. doi:10.1159/000321793

Bourke, M. E. in Grenyer, B. F. S. (2013). Therapists' accounts of psychotherapy process associated with treating patients with borderline personality disorder. Journal of Personality Disorders, 27(6), 735-745.

Clarkin, J. F., Yeomans, F. in Kernberg, O. F. (1999). Psychotherapy of Borderline Personality. New York, NY, ZDA: Wiley.

Davidson, K., Norrie, J., Tyrer, P., Gumley, A., Tata, P., Murray, H. in Palmer, S. (2006). The effectiveness of cognitive behavior therapy for borderline personality disorder: Results from the borderline personality disorder study of cognitive therapy (BOSCOT) trial. Journal of Personality Disorders, 20, 450-465.

Dixon-Gordon, K. L., Turner, B. J. in Chapman, A. L. (2011). Psychotherapy for personality disorders. International Review of Psychiatry, 23(May), 282302. doi:10.3109/09540261.2011.586992

Grant, B. F., Chou, S. P., Goldstein, R. B., Huang, B., Stinson, F. S., Saha, T. D., Smith, S. M., Dawson, D. A., Pulay, A. J., Pickering, R. P. in Ruan, W. J. (2008). Prevalence, correlates, disability, and comorbidity of DSM-IV borderline personality disorder: Results from the Wave 2 National Epidemiologic Survey on Alcohol and Related Conditions. The Journal of Clinical Psychiatry, 69(4), 533-45.

Harvey,R.,Black,D.W.inBlum, N.(2010). Systems Training for Emotional Predictability and Problem Solving (STEPPS) in the United Kingdom: A preliminary report. Journal of Contemporary Psychotherapy, 40(4), 225-232. doi:10.1007/s10879-010-9150-4

Hayes, S. C., Strosahl, K. in Wilson, K. G. (1999). Acceptance and Commitment Therapy: An experiential approach to behaviuor change. New York, NY, ZDA: Guilford Press.

Korzekwa,M.I., Dell,P.F., Links,P.S., Thabane,L.in Webb, S. P. (2008). Estimating the prevalence of borderline personality disorder in psychiatric outpatients using a two-phase procedure. Comprehensive Psychiatry, 49(4), 380-6. doi:10.1016/j.comppsych.2008.01.007

Linehan, M. M. (1993). Cognitive-behavioural treatment of borderline personality disorder. New York, NY, ZDA: Guildford Press.
Marziali, E. in Monroe-Blum, H. (1995). An interpersonal approach to group psychotherapy with borderline personality disorder. Journal of Personality Disorders, 9(3), 179-189.

Minuchin, S. (1974). Family and family therapy. Cambridge, MA, ZDA: Harvard University Press.

Pfohl, B. in Blum, N. (1997). Borderline evaluation of severity over time. Neobjavljen vprašalnik, Oddelek za psihiatrijo, Univerza v Iowi, Iowa, ZDA

Riemann, G., Weisscher, N., Goossens, P. J. J., Draijer, N., Apenhorst-Hol, M.in Kupka, R. W.(2014). Theaddition of STEPPS in the treatment of patients with bipolar disorder and comorbid borderline personality features: A protocol for a randomized controlled trial. $B M C$ Psychiatry, 14, 172. doi:10.1186/1471-244X-14-172

Ripoll, L. H. (2013). Psychopharmacologic treatment of borderline personality disorder. Dialogues in Clinical Neuroscience, 15(2), 213-24.

Shawe-Taylor, M., Geoghegan, M. in Hill, N. (v tisku). STEPPS Programme: Report on STEPPS outcomes - Working age adults, East locality. Notranje poročilo organizacije Surrey and Borders Partnership, NHS Foundation Trust. Leatherhead, Združeno kraljestvo: Surrey and Borders Partnership, NHS Foundation Trust.

Skodol, A. E., Buckley, P. in Charles, E. (1983). Is there a characteristic pattern to the treatment history of clinic outpatients with borderline personality? The Journal of Nervous and Mental Disease, 171(7), 405-10.

Tomko, R. L., Trull, T. J., Wood, P. K. in Sher, K. J. (2014). Characteristics of borderline personality disorder in a community sample: Comorbidity, treatment utilization, and general functioning. Journal of Personality Disorders, 28(5), 734-50. doi:10.1521/pedi_2012_26_093

Van Wel, B., Kockmann, I., Blum, N., Pfohl, B., Black, D. W. in Heesterman, W.(2006). STEPPS group treatment for borderline personality disorder in The Netherlands. Annals of Clinical Psychiatry: Official Journal of the American Academy of Clinical Psychiatrists, 18(1), 63-7. doi:10.1080/10401230500464760

Wells, A. (2009). Metacognitive therapy for anxiety and depression. New York, NY, ZDA: Guilford Press .

Widiger, T. A. in Weissman, M. M. (1991). Epidemiology of borderline personality disorder. Hospital \& Community Psychiatry, 42(10), 1015-21.

Yeomans F. E., Levy K. N. in Meehan, K. B. (2012). Treatment approaches for borderline personality disorder. Psychiatric Times, 42-47.

Young, J. E. (1999). Cognitive therapy for personality disorders: A schema-focused approach. Sarasota, FL, ZDA: Professional Resource Press.

Zanarini, M. C. (2009). Psychotherapy of borderline personality disorder. Acta Psychiatrica Scandinavica, 120(5), 373-7. doi:10.1111/j.1600-0447.2009.01448.x

Prispelo/Received: 16.2 .2015 Sprejeto/Accepted: 3.6 .2015 